\title{
Defined Contingent On Relationship
}

National Cancer Institute

\section{Source}

National Cancer Institute. Defined Contingent On Relationship. NCI Thesaurus. Code C93457.

A relationship between an activity and one of the following, where all activities are part of the global library of activities: The outcome of another activity where the source activity does not occur unless the target activity outcome has occurred; Another activity where the source activity does not occur unless the target activity has occurred; A group of other criteria that may be composed of a mix of other activities, observation results and/or other groups. 